\title{
THE LONG TERM EFFECTS OF SUBTLE TEMPERATURE RISES ON AQUATIC MICRO-ECOSYSTEMS
}

\author{
DICK DE ZWART \\ (University of Amsterdam, Dept. of Aquatic Ecology, Kruislaan 320, 1098 SM Amsterdam, \\ The Netherlands)
}

\section{SUMMARY}

Three-stage aquatic microcosms have been employed to investigate the long-term effects of subtle temperature rises. The type of microcosm used consists of three seperate aquaria, each representing one of the following trophic levels: autotrophs, herbivores and decomposers. The subsystems are interconnected by a pump-driven circulation flow. During a two-year experiment four of these systems have been subjected to a sequence of temperatures. Assuming the winter situation to be the most critical period regarding thermal pollution, the temperatures varied between $5^{\circ} \mathrm{C}$ and $17^{\circ} \mathrm{C}$. Each temperature has been sustained for a period of at least 100 days, to ensure the development of ecological relevant steady-states. The parameters observed, such as oxygen, phosphate and nitrate concentration, particle volume and zooplankton biomass, show a totally reversible effect to temperature in those cases that any effect is detectable. The systems show little "memory" in reacting to temperature alterations.

It can be concluded tentatively from part of all data that temperature rises of up to $8^{\circ} \mathrm{C}$ have no harmfull effects. Increasing the temperature to the absolute value of $17^{\circ} \mathrm{C}$ effected the phosphate metabolism of the micro-ecosystems.

A more extensive report, containing the fully analysed data and some remarks on the utility of microcosms in ecological impact studies, will be available on request from November 1979. 